\title{
ADSORCIÓN DE AZUL DE METILENO EN MEDIO ACUOSO EMPLEANDO CARBONES ACTIVADOS Y CARBONES ACTIVADOS MODIFICADOS CON NANOPARTÍCULAS DE ZnO
}

\author{
Diego Navarro Santos ${ }^{\mathrm{a}}$, Gerardo Cruz Cerro ${ }^{\mathrm{b}}$, John Rimaycuna Ramírez ${ }^{\mathrm{b}}$, José L. Solís ${ }^{\mathrm{a}}$, \\ Riitta Keiskic, Mónica M. Gómez ${ }^{\mathrm{a}^{*}}$
}

\begin{abstract}
RESUMEN
Carbones activados y carbones activados modificados con nanopartículas de $\mathrm{ZnO}$ fueron preparados mezclando residuos agroindustriales como coronta de maíz o pepa de ciruela con $\mathrm{ZnCl}_{2}$, como agente químico activador en una proporción en peso $1: 1$, o con $\mathrm{ZnCl}_{2}$, y acetato de zinc, en una proporción en peso 1:1:0,5 en medio acuoso, respectivamente. Con la masa pastosa resultante se hicieron pellets, los cuales fueron secados para luego ser carbonizados. El material resultante fue lavado varias veces con una solución $\mathrm{HCl} 0,5 \mathrm{M}$ y abundante agua destilada para luego ser secado a $100^{\circ} \mathrm{C}$ durante $12 \mathrm{~h}$. Finalmente, los pellets fueron molidos y tamizados dejando pasar tamaños menores a $0,25 \mathrm{~mm}$.

Microscopía electrónica de barrido de emisión de campo fue utilizada para la caracterización de las diferentes morfologías de las nanopartículas de $\mathrm{ZnO}$ en la superficie del carbón activado modificado que dependió de la materia prima empleada para la obtención del carbón activado, sin embargo en ambas se determinó la presencia del ZnO por difracción de rayos X. Los estudios cinéticos de adsorción con azul de metileno mostraron que el carbón activado modificado con $\mathrm{ZnO}$ procedente de la coronta de maíz mejora su proceso cinético con la presencia de la radiación UV. Sin embargo los carbones activados tienen mejores propiedades de adsorción que los modificados con $\mathrm{ZnO}$ debido a que las nanopartículas de $\mathrm{ZnO}$ cubrirían los sitios activos del carbón activado.
\end{abstract}

Palabras clave: nanopartículas de $\mathrm{ZnO}$, carbón activado, propiedades fotocatalíticas, adsorción.

\footnotetext{
a Facultad de Ciencias, Universidad Nacional de Ingeniería, Av. Túpac Amaru s/n, Lima 25, Perú, mgomez@uni.edu.pe

${ }^{\mathrm{b}}$ Facultad de Ciencias Agrarias, Universidad Nacional de Tumbes, Av. Universitaria s/n, Pampa Grande, Tumbes.

${ }^{\text {c } F a c u l t a d}$ de Tecnología, Universidad de Oulu, PO Box 4300, FI-90014, Finlandia.
} 


\title{
METHYLENE BLUE ADSORPTION IN AQUEOUS SOLUTION USING ACTIVATED CARBON AND ACTIVATED CARBON MODIFIED WITH ZnO NANOPARTICLES
}

\begin{abstract}
Activated carbons and activated carbons modified with $\mathrm{ZnO}$ nanoparticles were prepared mixing agricultural wastes like corn cob or red mombin seed with the activating chemical agent, $\mathrm{ZnCl}_{2}$, in a weight ratio 1:1 or with $\mathrm{ZnCl}_{2}$ and zinc acetate in a weight ratio 1:1:0.5 in aqueous medium, respectively. Pellets were obtained from this slurry and were dried before being carbonized. The resulting material was repeatedly washed with a solution of $\mathrm{HCl} 0,5 \mathrm{M}$ and abundant distilled water to finally be dried at $100^{\circ} \mathrm{C}$ for $12 \mathrm{~h}$ in the form of pellets, which were crushed and sieved to a size smaller than $0,25 \mathrm{~mm}$.

A Field Emission Scanning Electron Microscope was used to characterize the different morphologies of the $\mathrm{ZnO}$ nanoparticles on the surface of the obtained activated carbon which depended of the raw material used to produce the activated carbon, however in both samples the presence of $\mathrm{ZnO}$ was detected by X-ray diffraction.

Adsorption kinetic studies performed with methylene blue shown that the activated carbons based on corn cob, modified with $\mathrm{ZnO}$, improved its kinetic process under UV radiation. However bare activated carbons had better adsorption properties than the activated carbons modified with $\mathrm{ZnO}$ most probably due to the fact that $\mathrm{ZnO}$ nanoparticles could cover active sites of the activated carbon.
\end{abstract}

Key words: $\mathrm{ZnO}$ nanoparticles, activated carbon, photocatalytic properties, adsorption.

\section{INTRODUCCIÓN}

Actualmente, uno de los principales problemas ambientales en nuestro país y en el mundo es la contaminación de las fuentes de agua natural ${ }^{1,2}$, por lo que contaminantes, como metales pesados, generan una gran preocupación debido a la persistencia que presentan. Un incremento en el uso de metales pesados por parte de las industrias ha generado un incremento de la presencia de dichos metales en dichas fuentes de agua ${ }^{3,4}$. Diversos métodos como adsorción ${ }^{5}$, precipitación $^{6}$, filtración con membrana ${ }^{6}$ e intercambio iónico ${ }^{7}$ han sido utilizados ${ }^{8}$. Sin embargo, la adsorción ha probado ser la más económica y eficiente para remover metales pesados, contaminantes orgánicos y colorantes del agua contaminada ${ }^{9}$. Muchos adsorbentes como el carbón activado, silica y grafeno pueden ser utilizados en la purificación del agua ${ }^{3}$. De estos adsorbentes, el carbón activado ha demostrado ser el más eficiente en la remoción de una gran variedad de contaminantes orgánicos e inorgánicos presentes en el agua, debido a su estructura porosa bien desarrollada y a la presencia de un amplio espectro de grupos funcionales superficiales. Esto hace que sea capaz de distribuir los contaminantes en su gran superficie interna, haciéndolas accesibles a los grupos reactivos ${ }^{10}$. Una de las desventajas 
de la producción de carbón activado es el uso de materias primas no renovables para su producción, sin embargo el uso de residuos agrícolas se presenta como una alternativa viable técnica y económicamente ${ }^{11}$.

Siendo la agricultura una de las principales actividades económicas en el país, esto se presenta como una alternativa que permitiría reducir los impactos ambientales, dar mayor valor agregado a las materias primas y generar materiales que permitan el tratamiento de agua en áreas rurales y urbanas. Los carbones activados pueden ser modificados en base a distintos métodos químicos y físicos para mejorar sus propiedades y hacerlos más eficientes en el tratamiento de contaminantes específicos ${ }^{12}$. El óxido de zinc, $\mathrm{ZnO}$, es un fotocatalizador que puede ser usado también para descontaminación de aguas servidas o aguas para el consumo humano ${ }^{13}$. Se podría usar como material soporte el carbón activado y colocar nanopartículas de $\mathrm{ZnO}$ en su superficie. Al tener los dos materiales juntos, carbón activado y el $\mathrm{ZnO}$, se puede tener una sinergia entre ambos que puede complementar el proceso de adsorción con el de fotocatálisis.

El objetivo del presente trabajo fue obtener carbones activados o carbones activados modificados con nanopartículas de $\mathrm{ZnO}$ y evaluar su eficiencia para remover el colorante azul de metileno en solución acuosa.

\section{PARTE EXPERIMENTAL}

Para el presente trabajo, los desechos agroindustriales utilizados fueron la coronta de maíz (zea mays VAR) y la pepa de ciruela prunus domestica, los cuales fueron secados y tamizados a un tamaño menor a $0,5 \mathrm{~mm}$. Separadamente cada residuo fue mezclado con un agente activador, $\mathrm{ZnCl}_{2}$ en una proporción en peso de 1:1. Para conseguir la modificación del carbón activado se mezcló el residuo con el $\mathrm{ZnCl}_{2}$ y adicionalmente un agente modificante el $\mathrm{Zn}\left(\mathrm{O}_{2} \mathrm{CCH}_{3}\right)_{2}$ que se añadieron en una proporción en peso 1:1:0,5. Finalmente se adicionó suficiente agua destilada para formar una mezcla pastosa. Para obtener la forma de los pellets se procedió utilizando jeringas de $10 \mathrm{ml}$, a los cuales se les cortaron las puntas y con ayuda de un émbolo se compactó la masa pastosa dentro de ellas, quitándoles así el exceso de agua y dándoles la consistencia y forma adecuada (figura 1b). Estos pellets pasaron por un proceso de secado a $80^{\circ} \mathrm{C}$ por $12 \mathrm{~h}$ y luego fueron carbonizados en atmosfera de $\mathrm{N}_{2}$ en un horno tubular (figura 1a) a una temperatura de $600{ }^{\circ} \mathrm{C}$ durante $2 \mathrm{~h}$. Los pellets carbonizados fueron lavados repetidas veces con una solución de $\mathrm{HCl} 0,5 \mathrm{~N}$, agua destilada caliente y agua destilada fría para finalmente secarlos a $80^{\circ} \mathrm{C}$ por $12 \mathrm{~h}$ (figura $2 \mathrm{c}$ ), molidos y tamizados hasta un tamaño de partícula menor a $0,25 \mathrm{~mm}$. Los códigos utilizados para las muestras preparadas fueron los siguientes: CC para la muestra de carbón de coronta de maíz sin precursor (muestra sin modificar), CC/NP-ZnO para la muestra de carbón de coronta de maíz con la adición del precursor (muestra modificada), RMS para la muestra de carbón de pepa de ciruela sin precursor (muestra sin modificar) y RMS/NP-ZnO para la muestra de pepa de ciruela con la adición del precursor (muestra modificada). 

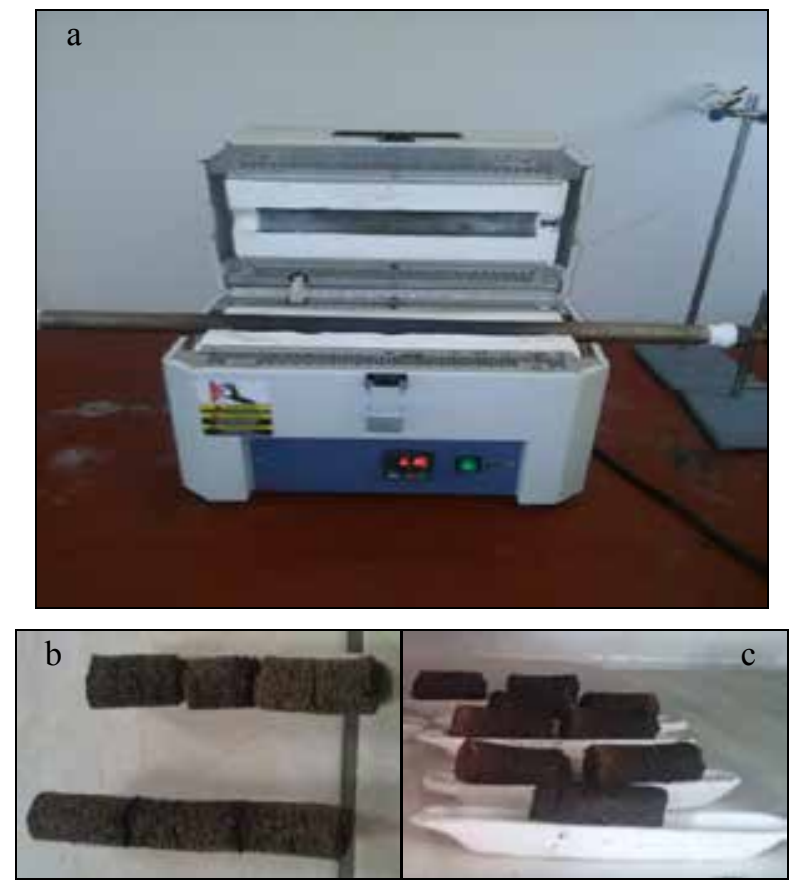

Figura 1. Imágenes relacionadas al proceso de obtención de los carbones activados: (a) Imagen del reactor donde fueron carbonizados los pellets, (b) pellets antes de ser carbonizados y (c) pellets carbonizados.

$\mathrm{El}$ estudio estructural de los carbones activados y carbones activados modificados con $\mathrm{ZnO}$ se realizó empleando un difractómetro de rayos X marca Siemens modelo D5000 operado con radiación $\mathrm{CuK} \alpha$. La morfología de las muestras se estudió por microscopía electrónica de barrido con emisión de campo usando un microscopio marca Zeiss modelo Ultra plus.

Se procedió a realizar el estudio cinético de adsorción y de adsorción-fotodegradación del azul de metileno en solución acuosa. Este colorante presenta la estructura química y peso molecular (MW) presentada en la figura 2.

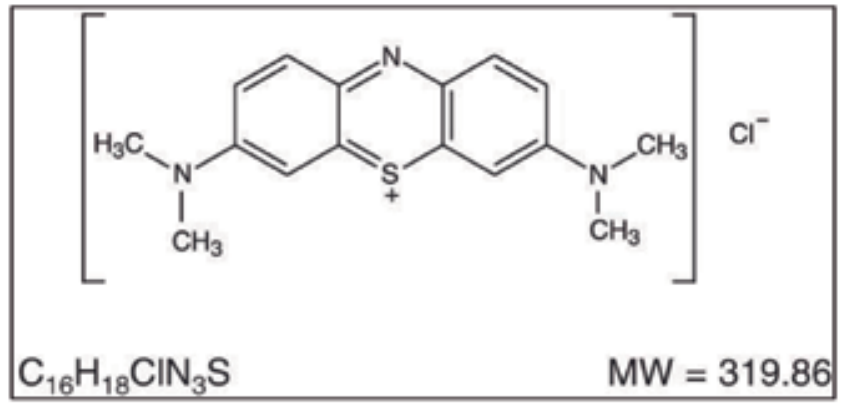

Figura 2. Colorante azul de metileno empleado para la determinación de adsorción/ fotodegradación de los carbones activados obtenidos. 
Para ello se utilizaron dos cámaras con sistemas de agitación magnética, uno con una fuente de luz UV, Ultra-Vitalux OSRAM $(220 \mathrm{~V}, 300 \mathrm{~W})^{14}$, y la otra en oscuridad absoluta. En ambos casos se utilizó un vaso de precipitado que contenía la solución de azul de metileno con una concentración inicial igual a 10 ppm para estudiar su cinética de adsorción y/o fotodegradación con los carbones activados en suspensión $(0,1 \mathrm{~g} / \mathrm{l})$ y constante agitación. Las tomas de muestra se realizaron a diferentes tiempos, sin detener la agitación del sistema y filtrando las alícuotas tomadas con un papel de filtro Whatman 41 (con retención de partículas entre 20 y $25 \mu \mathrm{m}$ ), empleando una jeringa, hasta completar un periodo de $300 \mathrm{~min}$. La concentración del colorante azul de metileno se evaluó por colorimetría empleando un espectrofotómetro UV-VIS Perkin Elmer Lambda 25 a una longitud de onda $(\lambda)$ de $664 \mathrm{~nm}$.

\section{RESULTADOS Y DISCUSIÓN}

Los carbones activados procedentes de pepa de ciruela sin modificar (RMS) y sus respectivos carbones modificados con nanopartículas de óxido de zinc (RMS/NPs-ZnO), así como los carbones procedentes de coronta de maíz sin modificar (CC) y sus respectivos carbones modificados con nanopartículas de óxido de zinc (CC/NPs-ZnO), fueron caracterizados estructuralmente por difracción de rayos X. La figura 3 muestra el difractograma de las muestras RMS y RMS/NPs-ZnO. Se puede observar que la muestra sin modificar presenta mayoritariamente el cuarzo $\left(\mathrm{SiO}_{2}\right)$ identificado por los picos asignados por $\left(^{*}\right)$. El silicio es un elemento común en la composición de estos materiales vegetales y se oxida formando $\mathrm{SiO}_{2}$ en el proceso de carbonización por las altas temperaturas a las cuales se realiza el proceso, por lo que se obtendría como un producto secundario del proceso. Adicionalmente se observan los tres picos característicos del $\mathrm{ZnO}$, que es un producto remanente de la activación. Por otro lado, la muestra modificada (RMS/NPs-ZnO) tiene claramente los picos correspondientes a las fases correspondientes al $\mathrm{SiO}_{2}$, y la fase wurzita del $\mathrm{ZnO}$.

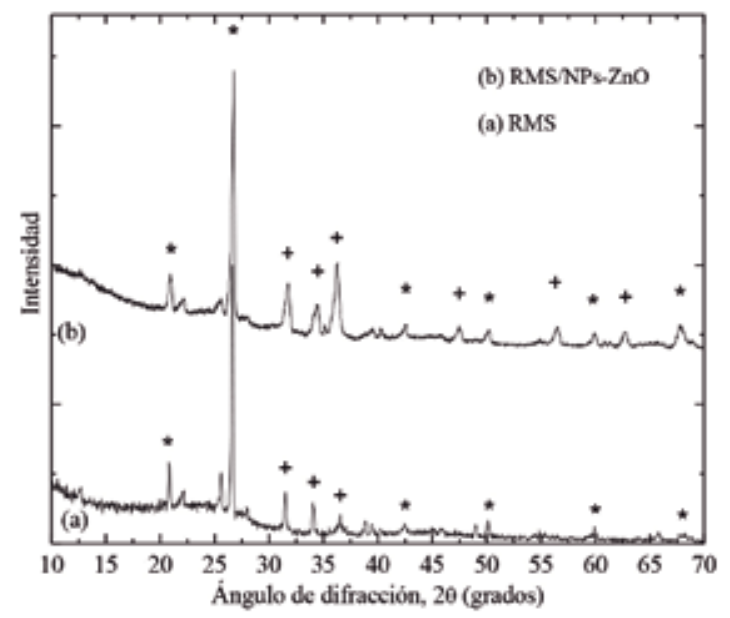

Figura 3. Difractogramas de rayos $X$ para los carbones activados: (a) procedentes de pepa de ciruela sin modificante (RMS) y (b) modificados con nanopartículas de $\mathrm{ZnO}$ (RMS/NPs-ZnO.

Los picos señalados se asignan a reflexiones de los compuestos: (*) $\mathrm{SiO}_{2}$ y (+) al $\mathrm{ZnO}$. 
Los difractogramas correspondiente a las muestras $\mathrm{CC}$ y $\mathrm{CC} / \mathrm{NPs}-\mathrm{ZnO}$ se presentan en la figura 4. La muestra sin modificar presenta algunos picos característicos del $\mathrm{SiO}_{2}$ y un pico del $\mathrm{ZnO}$ (Fig. 4a), mientras que la muestra modificada presenta las fases de $\mathrm{SiO}_{2}$ y el $\mathrm{ZnO}$ (Fig. 4b).

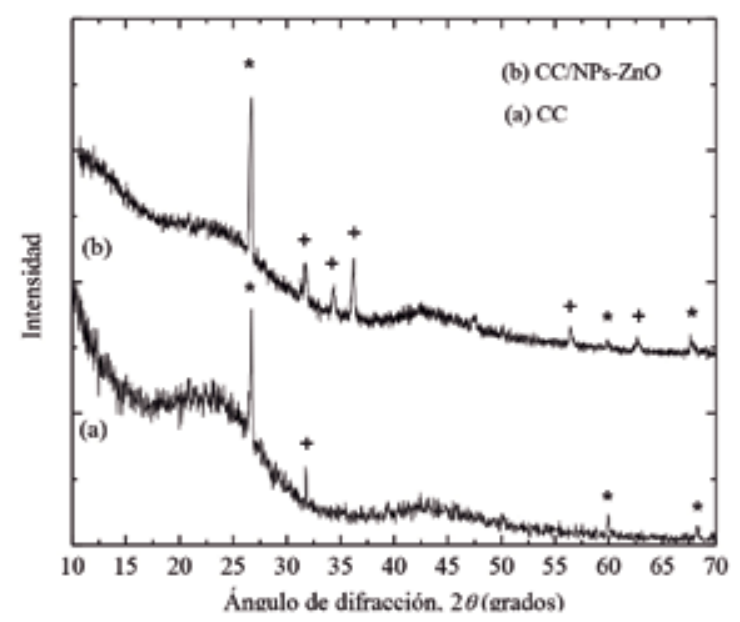

Figura 4. Difractogramas de rayos $X$ para los carbones activados: (a) procedentes de coronta de maíz sin modificante (CC) y (b) modificados con nanopartículas de $\mathrm{ZnO}$ (CC/NPs-ZnO).

Los picos señalados se asignan a reflexiones de los compuestos: (*) $\mathrm{SiO}_{2}$ y (+) al $\mathrm{ZnO}$.

El estudio morfológico de los carbones activados obtenidos de la pepa de ciruela se muestra en la figura 5, donde se presentan las micrografías para el carbón activado sin modificar RMS (Fig. 5a) y el carbón activado modificado RMS/NPs- $\mathrm{ZnO}_{2}$ (Fig. 5b). Se puede apreciar claramente la presencia de cristales columnares correspondientes al $\mathrm{ZnO}$ sobre la superficie de ambos carbones activados. Para la muestra RMS la columna cristalina posee un diámetro aproximado de $1 \mu \mathrm{m}$, mientras que para RMS/NPs-ZnO2 este valor es menor y se encuentra en el orden de $500 \mathrm{~nm}$. Además, para el carbón activado modificado la cantidad de $\mathrm{ZnO}$ es mayor respecto para el caso del carbón activado sin modificar.

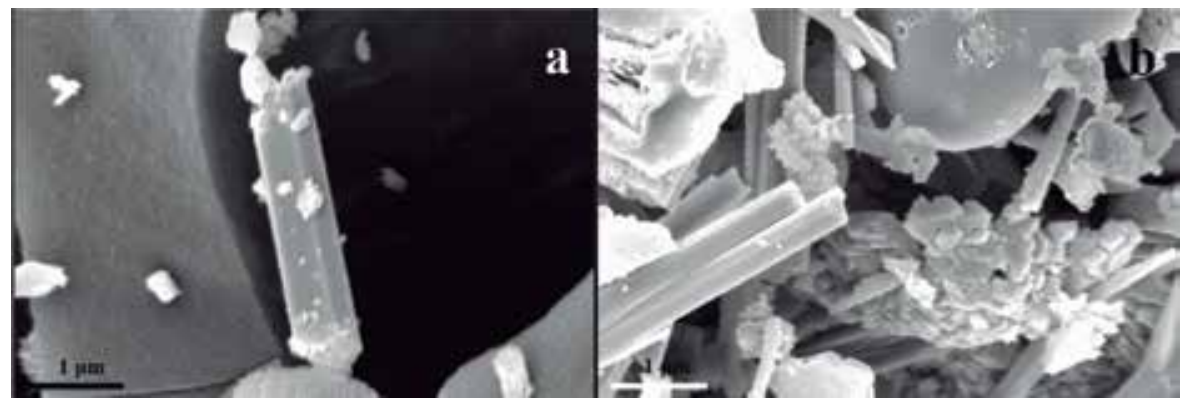

Figura 5. Micrografías electrónicas de emisión de campo de los carbones activados (a) RMS (b) RMS/NPs-ZnO. 
La figura 6 presenta las micrografías para los carbones activados provenientes de la coronta de maíz sin modificar CC (Fig. 6a) y modificado CC/NPs- ZnO (Fig. 6b). La información correspondiente $\mathrm{CC}$ muestra una superficie bastante lisa con una cavidad prominente que posee un diámetro aproximado de $4 \mu \mathrm{m}$, se observa que hay partículas sobre superficie que pueden corresponder al $\mathrm{ZnO}$. La muestra CC/NPs- $\mathrm{ZnO}$ presenta un material de gran porosidad que se encuentra sobre la superficie lisa correspondiente al carbón, el cual debe de corresponder al $\mathrm{ZnO}$.

Se observa que para el caso de los carbones modificados de ambas materias primas las nanopartículas de $\mathrm{ZnO}$ bloquean los poros de los carbones, lo que reduciría los sitios activos para la adsorción de los contaminantes.

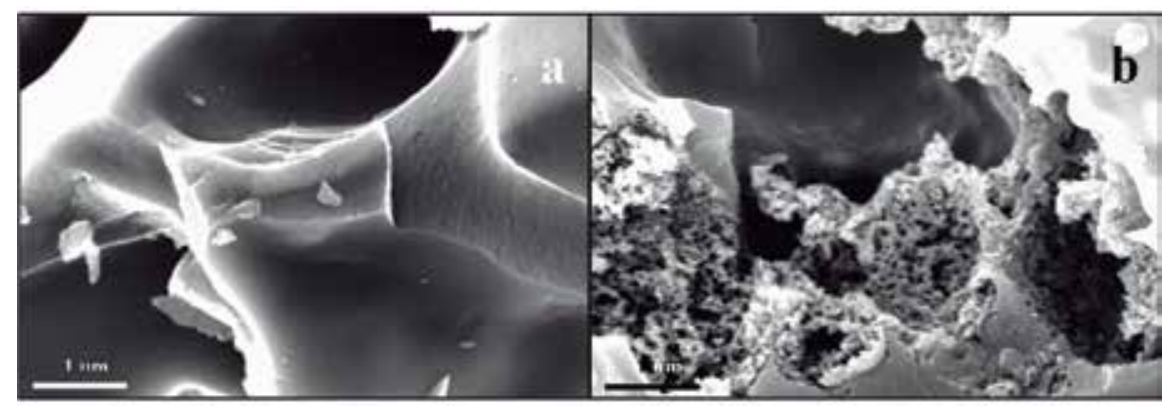

Figura 6. Micrografías electrónicas de emisión de campo de los carbones activados (a) CC y (b) $\mathrm{CC} / \mathrm{NPs}-\mathrm{ZnO}_{2}$.

Los resultados obtenidos de las pruebas de remoción de azul de metileno a diferentes condiciones (con y sin luz UV) para los carbones activados obtenidos a partir de la pepa de ciruela (RMS y RMS/NPs-ZnO) se muestran en la figura 7. En la comparación del carbón RMS con el carbón modificado RMS/NPs-ZnO se puede observar que el primero presenta mejor eficiencia (mayor \% de remoción del colorante) en condiciones con y sin luz UV (figuras 7a y 7c). Sin embargo, al evaluar la eficiencia en presencia de luz UV de ambos carbones (figuras $7 \mathrm{~b}$ y 7d) observamos que este factor no es significativamente influyente ya que en el caso de la muestra sin modificar sólo hay un ligero aumento de la eficiencia mientras que para el carbón activo modificado no existe variación alguna en su eficiencia. 

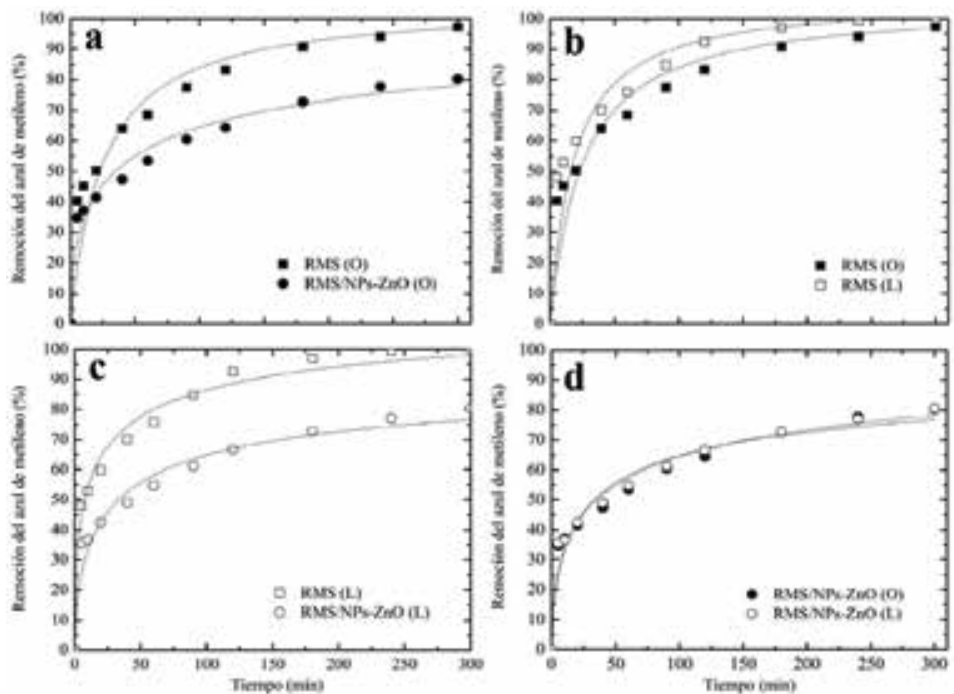

Figura 7. Remoción del azul de metileno para los carbones activados procedentes de pepa de ciruela sin proceso de modificación (RMS) y modificados con nanopartículas de óxido de zinc (RMS/NPs-ZnO). Evaluados en presencia de luz (L) y en oscuridad (O).

Caso similar ocurre en los carbones activos obtenidos a partir de la coronta de maíz (CC y $\mathrm{CC} / \mathrm{NPs}-\mathrm{ZnO}$ ). En la figura 8 observamos que la muestra $\mathrm{CC}$ es más eficiente que la muestra modificada CC/NPs-ZnO con y sin luz UV (figuras 8a y 8c). Por otra parte, la presencia de luz UV en estos carbones produce un cambio notorio en su eficiencia incrementado el $\%$ de remoción del colorante (figuras $8 \mathrm{~b}$ y $8 \mathrm{~d}$ ).
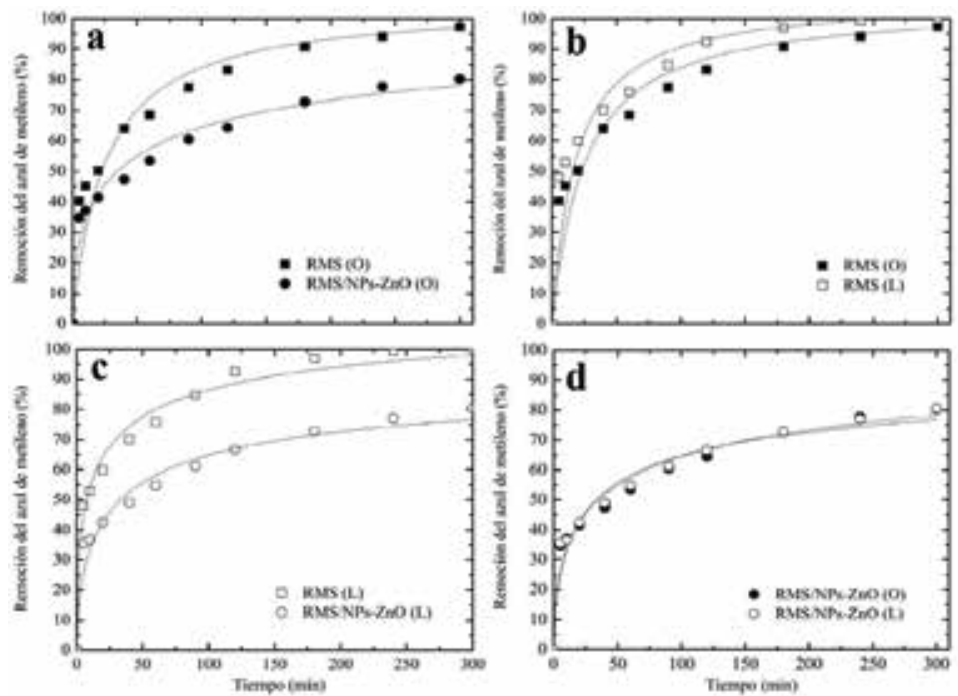

Figura 8. Remoción del azul de metileno para los carbones activados procedentes de coronta de choclo sin proceso de modificación (CC) y modificados con nanopartículas de óxido de zinc (CC/NPs-ZnO). Evaluados en presencia de luz (L) y en oscuridad (O). 
En la tabla 1 se aprecian los parámetros de los modelos cinéticos de pseudo-primer y pseudosegundo orden aplicados a los datos de las curvas de remoción de azul de metileno de las muestras estudiadas, identificándose que los datos de remoción se ajustan mejor a al segundo modelo analizado con $\mathrm{R}^{2}$ entre 0.9867 - 0.9995. El ajuste al modelo de pseudo-segundo orden significaría que la interacción entre el azul de metileno y los carbones activados es de naturaleza química ${ }^{15}$.

Tabla 1. Parámetros de los modelos cinéticos de pseudo-primer y pseudo-segundo orden aplicados a los datos de las curvas de remoción de azul de metileno de las muestras estudiadas

\begin{tabular}{|c|c|c|c|c|c|c|c|c|}
\hline \multicolumn{9}{|c|}{ Modelo de Pseudo-primer orden } \\
\hline \multirow[b]{2}{*}{ Parameter } & \multirow[b]{2}{*}{$\mathrm{CC}$} & \multicolumn{2}{|l|}{ CC/NPs- } & \multicolumn{2}{|l|}{ RMS/NPs- } & \multirow{2}{*}{$\begin{array}{l}\text { CC/NPs- } \\
\mathrm{ZnO}(\mathrm{L})\end{array}$} & \multirow{2}{*}{$\begin{array}{c}\text { RMS } \\
\text { (L) }\end{array}$} & \multirow{2}{*}{$\begin{array}{c}\text { RMS/NPs- } \\
\mathrm{ZnO}(\mathrm{L})\end{array}$} \\
\hline & & $\mathrm{ZnO}$ & RMS & $\mathrm{ZnO}$ & $\mathrm{CC}(\mathrm{L})$ & & & \\
\hline$q_{1}$ & 1,71 & 2,67 & 1,70 & 1,95 & 2,78 & 1,66 & 1,56 & 2,05 \\
\hline$q_{1}$ exp) & 0,87 & 0,68 & 0,89 & 0,72 & 0,85 & 0,86 & 0,91 & 0,73 \\
\hline$K_{1}$ & 0,03 & 0,01 & 0,02 & 0,02 & 0,04 & 0,02 & 0,03 & 0,02 \\
\hline$R^{2}$ & 0,9648 & 0,7865 & 0,9781 & 0,9681 & 0,8612 & 0,9766 & 0,9795 & 0,9722 \\
\hline \multicolumn{9}{|c|}{ Modelo de pseudo-segundo } \\
\hline & & CC/NPs- & & RMS/NPs- & & CC/NPs- & RMS & RMS/NPs- \\
\hline Parameter & $\mathrm{CC}$ & $\mathrm{ZnO}$ & RMS & $\mathrm{ZnO}$ & $\mathrm{CC}(\mathrm{L})$ & $\mathrm{ZnO}(\mathrm{L})$ & (L) & $\mathrm{ZnO}(\mathrm{L})$ \\
\hline$q_{e}$ & 0,90 & 0,69 & 0,90 & 0,74 & 0,87 & 0,88 & 0,94 & 0,75 \\
\hline$K_{2}$ & 0,09 & 0,09 & 0,09 & 0,07 & 0,24 & 0,06 & 0,09 & 0,07 \\
\hline$R^{2}$ & 0,9960 & 0,9811 & 0,9966 & 0,9867 & 0,9995 & 0,9900 & 0,9961 & 0,9893 \\
\hline
\end{tabular}

Resumiendo lo encontrado en la prueba de cinética, los carbonos activados presentan una mayor eficiencia para remover el colorante que los carbonos activados modificados con $\mathrm{ZnO}$; y a su vez, esta eficiencia aumenta en presencia de luz UV (lo cual se aprecia mejor en los carbones obtenidos de la coronta de choclo).

\section{CONCLUSIONES}

Se modificaron carbones activados producidos a partir de residuos de coronta de maíz y pepa de ciruela con nanopartículas de $\mathrm{ZnO}$, las cuales están presentes en la superficie de los carbones activados.

La cinética de adsorción de los carbones activados modificados con $\mathrm{ZnO}$ procedente de la coronta de maíz mejora con la presencia de radiación UV en el proceso. Sin embargo los carbones activados adsorben mejor que los modificados con $\mathrm{ZnO}$ debido a que las nanopartículas de $\mathrm{ZnO}$ bloquean parcialmente los poros del carbón activado y el acceso a 
los sitios activos.

Los datos de remoción de azul de metileno por las muestras de carbones activados con y sin modificar se ajustaron al modelo cinético de pseudo-segundo orden evidenciando una interacción de tipo química.

\section{AGRADECIMIENTO}

El presente trabajo fue desarrollado bajo el auspicio de la Universidad Nacional de Tumbes (Proyecto Canon Resolución $\mathrm{N}^{\circ}$ 0722-2014/UNT-R) y del proyecto AdMatU financiado por la Academia de Finlandia. Uno de nosotros (M.M.G.) agradece al Instituto General de Investigación de la Universidad Nacional de Ingeniería por la financiación otorgada como Docente Investigador.

\section{REFERENCIAS BIBLIOGRÁFICAS}

1. Vörösmarty CJ, McIntyre PB, Gessner MO, Dudgeon D, Prusevich A, Green P, Glidden S, Bunn SE, Sullivan CA, Liermann CR, Davies PM. Global threats to human water security and river biodiversity. Nature. 2010; 467(7315): 555-61.

2. Ocola JJ. Protección del agua - vigilancia y control de vertimientos - paver. [en línea]. Lima: Autoridad Nacional del Agua; 2015. [accesado 08 de diciembre del 2015]. Disponible en: http://www.ana.gob.pe/media/353227/4-protecci\%C3\%B3n\%20del\%20 agua $\% 20$ vigilancia $\% \quad$ 20y\%20control\%20de $\% 20$ vertimientos $\% 20$ paver. $\% 20 \% 20$ lic.\%20juan\%20ocola.pdf

3. Immamuglu M, Tekir O. Removal of copper (II) and lead (II) ions from aqueous solutions by adsorption on activated carbon from a new precursor hazelnut husks. Desalination. 2008; 228:108-113.

4. Kadirvelu K, Goe J, Rajagopal C. Sorption of lead, mercury and cadmium ions in multicomponent system using carbon aerogel as adsorbent. J Hazard Mater. 2008; 153:502507.

5. Sing KSW. Adsorption methods for the characterization of porous materials. Adv Colloid Interface Sci. 1998; 76-77: 3-11.

6. Abdel Salam OE, Reiad NA, ElShafei MM. A study of the removal characteristics of heavy metals from wastewater by low-cost adsorbents. J Adv Res. 2011; 2: 297-303.

7. Rengaraj S, Kyeong-Ho Y, Seung-Hyeon M. Removal of chromium from water and wastewater by ion exchange resins. J Hazard Mater. 2001; 87(1): 273- 287.

8. Chingombe P, Saha B, Wakeman R. Surface modification and characterization of a coalbased activated carbon. Carbon 2005; 43:3132-3143.

9. Tangjuank S, Insuk N, Tontrakoon J, Udeye V. Adsorption of lead (II) Cadmium (II) ions from aqueous solutions by adsorption on activated carbon prepared from cashew nut shells. World Acad Sci Eng Technol. 2009; 52:110-116.

10. Liu Q-S, Zheng T, Wang P, Jiang J-P, Li N. Adsorption isotherm, kinetic and mechanism studies of some substituted phenols on activated carbon fibers. Chem Eng J. 2010; 
157:348-356.

11. Cruz GJF, Matějová L, Pirilä M, Ainassaari K, Canepa CA, Solis J, et al. A Comparative Study on Activated Carbons Derived from a Broad Range of Agro-industrial Wastes in Removal of Large-Molecular-Size Organic Pollutants in Aqueous Phase. Water Air Soil Pollut. 2015; 226(7): 1-15.

12. Bhatnagar A, Hogland W, Marques M, Sillanpaa M. An overview of the modification methods of activated carbon for its water treatment applications. Chem Eng J. 2013; 219:499-511.

13. Hoffmann MR, Martin ST, Choi W, Bahnemann DW. Environmental applications of semiconductor photocatalysis. Chem Rev. 1995; 95:69-96.

14. Colonia R, Solís J, Gómez M. Síntesis de nanopartículas de $\mathrm{ZnO} 2$ empleando ultrasonido: caracterización estructural y morfológica para aplicaciones bactericidas. Rev Soc Quím Perú. 2013; 79(2): 126-135.

15. Ho YS, McKay G. Pseudo-second order model for sorption processes. Process Biochem. 1999; 34(5): 451-465 